\title{
Métodos de ensino integrados em monitoria de anatomia e Histologia: um relato de experiência
}

\author{
Integrated teaching methods in anatomy monitoring and histology: a report of experience
}

Métodos de enseñanza integrados en el monitoreo de la anatomía histología: un relato de experiencia

Gustavo Nunes Mesquita ${ }^{1 *}$, Julia Gonçalves Oliveira1, Ana Lúcia Naves Alves², Laisa Marcato Souza da Silva ${ }^{1}$, Luiz Henrique dos Santos Ribeiro ${ }^{3}$, Thiago de Oliveira Silveira' ${ }^{1}$.

\section{RESUMO}

Objetivo: refletir a importância de métodos de ensino didáticos e o uso de metodologias ativas de ensino dentro das monitorias acadêmicas, relatar a vivência dos acadêmicos nos aspectos de ensino dentro do curso de graduação em enfermagem, fisioterapia e farmácia. Metodologia: trata-se de um relato de experiência abordando a prática de metodologias ativas de ensino e integração entre conteúdo das disciplinas no programa de monitoria acadêmica. Relato de experiência: uso de ensino integrado e metodologias ativas de ensino para três cursos de graduação, sendo eles farmácia, enfermagem e fisioterapia. Conclusão: a monitoria trate-se um instrumento fundamental na formação do acadêmico tanto pela dinâmica do aprendizado, como pela sua atuação junto ao docente e os demais alunos e seu reflexo positivo no desempenho do acadêmico.

Palavras-chave: Ensino, Educação em Enfermagem, Bacharelado em Enfermagem.

\section{ABSTRACT}

Objective: To reflect the importance of didactic teaching methods and the use of active teaching methodologies within academic monitoring, to report the experience of academics in teaching aspects within the undergraduate nursing, physiotherapy and pharmacy courses. Methodology: This is an experience report addressing the practice of active teaching methodologies and integration between subject content in the academic monitoring program. Experience report: use of integrated teaching and active teaching methodologies for three undergraduate courses, namely pharmacy, nursing and physiotherapy. Conclusion: monitoring is a fundamental instrument in the formation of the academic both by the dynamics of learning, as well as by its performance with the teacher and the other students and its positive reflection on the academic performance.

Keywords: Teaching, Nursing Education, Bachelor of Nursing.

\section{RESUMEN}

Objetivo: Reflejar la importancia de los métodos de enseñanza didáctica y el uso de metodologías de enseñanza activa dentro del monitoreo académico, para informar la experiencia de los académicos en aspectos de enseñanza dentro de los cursos de pregrado de enfermería, fisioterapia y farmacia. Metodología: Este es un informe de experiencia que aborda la práctica de metodologías de enseñanza activa y la

\footnotetext{
${ }^{1}$ Centro Universitário de Barra Mansa, (UBM). Barra Mansa-RJ. *E-mail: gustavomesquita113@gmail.com 2Facultad de Humanidades Y Artes, (UNR), Argentina.

3Universidad Federal Fluminence, (UFF), Niteroi-RJ.
} 
integración entre el contenido de la asignatura en el programa de monitoreo académico. Relato de experiencia: uso de la enseñanza integrada y metodologías de enseñanza activa para tres cursos de pregrado, a saber, farmacia, enfermería y fisioterapia. Conclusión: el monitoreo es un instrumento fundamental en la formación de lo académico tanto por la dinámica del aprendizaje, como por su desempeño con el profesor y los demás alumnos y su reflexión positiva sobre el desempeño académico.

Palabras clave: Docencia, Educación en Enfermería, Licenciatura en Enfermería.

\section{INTRODUÇÃO}

A monitoria acadêmica durante a graduação é uma oportunidade para os estudantes desenvolverem habilidades de docência e conhecimento aprofundado de determinado assunto e ou matéria, contribuindo para o processo de aprendizagem de monitores e alunos, além disso é importante salientar que esta prática foi oficializada no Brasil no art. 41 da Lei n. $-5.540 / 68$ e ratificada no art. 84 da Lei n. -9.394 , de 20 de dezembro de 1996, chamada de Lei de Diretrizes e Bases da Educação Nacional (LDB). Esta lei conta com o aproveitamento de estudantes de graduação em atividades dentro do ramo de pesquisa, ensino e extensão conforme o decreto que delegam às instituições de ensino superior (IES) (RAMOS LAV et al., 2012).

A monitoria é uma atividade que deve ser desenvolvida em parceria entre o estudante monitor e professororientador, ou seja, o programa de monitoria deve estar direcionado juntamente com a metodologia de disciplina do professor, dessa forma o professor orientador da disciplina deve atuar como mediador na produção do conhecimento e a presença do monitor na disciplina traz concretamente a possibilidade de acompanhar "mais de perto" o processo de aprendizagem dos alunos e o desenvolvimento acadêmico do mesmo, servindo de porta-voz do grupo de estudos (ASSIS FD. 2006).

Dessa forma, buscando um direcionamento no aprendizado durante a graduação teórico-prático, se discute a sua formação pedagógica dos docentes, pois para que as instituições formem profissionais com senso crítico e as mais diversas qualidades que um profissional pode ter, primeiro deve-se rever a formação dos docentes que formam esses profissionais (NUNES ECDA, SILVA LW, PIRES EPOR., 2011).

Analisando o cenário atual de ensinos superiores no Brasil, é provável observar a maneira como ocorre à formação de professores universitários, principalmente na área de saúde, no que diz respeito ao conhecimento de didática pedagógica. Sabe-se que os professores atuais de ensino superior são em sua grande maioria mestres e doutores em determinada área e/ou disciplina, possuindo um vasto conhecimento e experiência no ramo onde atuam. Apesar disto, a monitoria favorece uma grande experiência aos monitores dentro da metodologia de ensino e despertando aos alunos o interesse pela formação de professor e desenvolvimento didático (PELEIAS IR et al., 2015)

Portanto, com o propósito educacional, alguns pontos práticos de cursos graduação da saúde devem ser respeitados, tais como as peculiaridades de cada contexto educacional, com diferentes aspectos a serem mensurados. Considerando que no processo de ensino-aprendizagem deve-se frisar a participação direta integral do professor na orientação ao monitor (MESSIAS M et al., 2015).

O aluno-monitor é o estudante que, por algum interesse, aproxima-se de uma disciplina e ajuda o professor no ensino aos demais alunos, desenvolvendo trabalho ou pequenas tarefas. Como monitor, destaca-se a importância dessa atividade para o desenvolvimento de habilidades técnicas e práticas; a oportunidade de obter um contato mais próximo com a docência; a possibilidade de rever os conteúdos anteriormente aprendidos e de relacionar-se com outros estudantes. Importante salientar, é que os alunos se sentem mais confortáveis a fazer questionamentos ao monitor e que na maioria das vezes serve de intermediário entre o professor e os estudantes.

Desse modo, a presente pesquisa tem como demonstrar e refletir a importância de métodos de ensino didáticos e o uso de metodologias ativas de ensino dentro das monitorias acadêmicas, relatar a vivência dos acadêmicos nos aspectos de ensino dentro do curso de graduação em enfermagem, fisioterapia e farmácia. 


\section{MÉTODOS}

Trata-se de um relato de experiência que aborda prática de metodologias ativas de ensino e integração entre conteúdo das disciplinas no programa de monitoria acadêmica das seguintes disciplinas, Anatomofisiologia do Sistema Locomotor, Tecidos Corporais I, Anatomofisiologia dos Sistemas Cardiovasculares e Respiratórios, Tecidos Corporais II, do ano de 2018 de uma instituição de ensino superior na região do médio Paraíba, para o primeiro e segundo período dos cursos de enfermagem, farmácia e fisioterapia.

\section{RELATO DE EXPERIÊNCIA}

O uso de ensino integrado se iniciou no mês de fevereiro de 2018, concomitantemente com o início programa de monitoria multidisciplinar para alunos de ensino superior dos cursos de enfermagem, farmácia e fisioterapia; Onde foi selecionado pela coordenação do curso de enfermagem através de análise do coeficiente de rendimento e entrevista um acadêmico dentre os inscritos para ser monitor das disciplinas Anatomofisiologia do Sistema Locomotor, Tecidos Corporais I, Anatomofisiologia dos Sistemas Cardiovasculares e Respiratórios, Tecidos Corporais II durante o ano de 2018, para as turmas de farmácia, enfermagem e fisioterapia de primeiro e segundo período.

O termo integração traz a ideia de junção e ou aglutinação e foi esta a proposta em que foram fundamentadas as metodologias de ensino das aulas, que procuravam integrar os conhecimentos de anatomia e histologia. As aulas eram limitadas a 2 horas de estudos com pausas para descanso tanto dos alunos quanto do monitor.

Dentre os métodos utilizados para integrar os conhecimentos, um dos mais importantes foram os estudos sequenciais dos dois conteúdos no mesmo dia com o critério dos assuntos serem dos mesmos sistemas do corpo humano, para que os alunos assimilassem um conteúdo ao outro e entendessem de forma mais profunda a complexidade do tema abordado em aula, além disso foi fornecido de material didático simplificado e foram indicados livros referenciais para a matéria, que eram atlas de anatomia e histologia, com intuito de estimular os alunos a buscar conhecimento de forma autônoma, ou seja, fora de horário de aula, todos os materiais foram fornecidos por plataformas digitais gratuitas e online.

Ademais, foi utilizada a metodologia de ensino sala de aula invertida ou flipped classroom, que possui várias interpretações, mas nesta experiência consistiu em consiste em estimular os alunos a absorver o conteúdo por meio digital antes da aula presencial, para que já chegassem na aula com o conhecimento minimamente assimilado sobre o assunto a ser debatido para uma melhor fixação do conteúdo como um todo, os planos de aula dos professores oficiais das disciplinas foram seguidos e a monitoria era realizada após a aula do conteúdo e da disponibilização dos materiais e livros online referentes às disciplinas já ensinadas pelos professores oficiais das disciplinas, além de vídeos curtos (VARGAS CP et al, 2018). Outro método utilizado foi o incentivo do monitor para que os alunos assumissem o papel de ensinar outros alunos no momento em que estivessem seguros dos conhecimentos já adquiridos, com o intuito de incentivar a docência nos acadêmicos que frequentavam as aulas e ajudá-los a fixar ainda mais os conteúdos compartilhados.

Todos os alunos tinham acesso a meios digitais para entrar em contato diretamente com o monitor da matéria e tirar dúvida 24 horas por dia, além disso durante e experiência a todos os alunos que participaram ativamente do programa de monitoria utilizaram as ferramentas disponibilizadas. Houveram relatos dos alunos de melhora nos desempenhos das disciplinas ensinadas, além de ganho na autonomia de estudo e vontade de executar a docência, já para o aluno monitor o foi grande o ganho em experiência para a docência e no uso de diferentes metodologias de ensino.

\section{DISCUSSÃO}

A disponibilidade de monitores no ensino superior para acadêmicos no início de suas atividades acadêmicas, é de grande valia acrescentando de forma significativa valores para sua formação, pois observase grandes anseios e dificuldades em sua adaptação ao meio acadêmico. 
De certo modo as monitorias contribuem para amenizar e tranquilizar as expectativas dos acadêmicos, ao compartilhar seus conhecimentos e dificuldades já vivenciadas pelos monitores, gera-se um impacto positivo no aprendizado desses discentes.

Segundo Assis FD et al., (2006) dissertam que a monitoria se configura como uma iniciativa relevante no ambiente universitário, pois tais atividades envolvem o desenvolvimento de ações que fortalecem a formação do aluno em diferentes dimensões, ao mesmo tempo em que the proporciona a possibilidade de ampliar o conhecimento, desenvolvendo suas habilidades e aptidões para o campo do ensino. Pois, a monitoria tem como fundamentos o estabelecimento de planos de aulas, planos pedagógicos, metas educacionais e a identificação das dificuldades e perfil dos alunos (VICENZI CB, et al.,2016).

Devido a isso, a interação entre aluno, monitor e docente facilita o nivelamento em relação ao aprendizado, pois irá identificar suas necessidades e dificuldades buscando de forma efetiva traçar uma metodologia de ensino que potencialize o aprendizado.

Destaca-se a importância da interação do monitor junto ao corpo docente, aos demais acadêmicos e ao próprio curso, pois essa experiência o oportunizou vivenciar e permanecer no espaço da universidade, tornando-o mais participante da vida acadêmica, e dos processos educativos, assim como da responsabilidade de ser monitor (WAGNER F, LIMA IAX, TURNES BL; 2012).

O método utilizado para o desenvolvimento das atividades na monitoria foi a metodologia ativa, que estimula a busca pelo conhecimento através dos temas abordados entre os alunos, potencializando que os mesmos busquem conhecimentos, informações e compartilhem em sala para estimular o senso crítico.

Para Berbel NAN (2011), o método ativo é um processo que visa estimular a autoaprendizagem e a curiosidade do estudante para pesquisar, refletir e analisar possíveis situações para tomada de decisão, sendo o professor apenas o facilitador desse processo.

A monitoria permite ampliar a visão em relação ao aluno, pois auxiliá-los na busca pelo conhecimento e usar ferramentas para associar a teoria à prática estimula na contribuição do ensino. Sendo necessário o resgate desse conhecimento para o estágio onde irá aplicar de forma efetiva para o bom desenvolvimento em prática, sendo crítico e resolutivo de acordo com a demanda apresentada.

Desta forma, segundo Pellison EF et. al, (2004), permite a ocorrência de uma melhor correlação entre teoria e prática, possibilitando que durante o processo de ensino e aprendizagem, seja criado um espaço onde o aluno possa interrogar, praticar e revisar conteúdos trabalhados em sala de aula com menor grau de receio, favorecendo assim, um maior nível de confiança quanto à realização dos procedimentos.

O aluno que possui o auxílio do monitor acaba dispondo de mais oportunidades para esclarecimento de dúvidas quanto ao conteúdo programático da disciplina reforçando o aprendizado. Porém existem alguns alunos que de certa forma negligenciam o suporte oferecido pelo monitor por diversas causas distintas e não absorvem o apoio que thes é ofertado (STEINDORFF G et al., 2016). Orientar os alunos sobre a importância da monitoria se faz necessário, para melhor entendimento da proposta a qual está sendo ofertada, informando que será uma troca de informações e que todos estão na mesma posição de ampliar, aprender e aperfeiçoar seus conhecimentos. Com objetivo de fornecer ferramentas para facilitar o aprendizado e prepará-los de forma adequada para a formação acadêmica.

De acordo com Fernandes NC (2004), o aluno de graduação ao se adaptar ao processo de aprendizagem busca novos conhecimentos por meio da leitura e pesquisa, além da formação do pensamento crítico e investigativo, que podem direcionar a educação permanente. Portanto verifica-se que alunos participantes da monitoria encontrarão vantagens pedagógicas, na medida em que tem um aprendizado mais ativo, interativo e imediato, fato que favorece um maior domínio no processo de aprendizagem (NATÁRIO EG, SANTOS AAA, 2010).

Para Batista JB e Frison LMBF (2009), a monitoria tende a ser representada como uma tarefa que solicita competências do monitor para atuar como mediador da aprendizagem dos colegas, contando, para sua consecução, com a dedicação, o interesse e a disponibilidade dos envolvidos. 
Desta forma a monitoria representa uma ferramenta importantíssima para o aprendizado dos alunos podendo sanar suas dúvidas, ampliar seus conhecimentos e estarem mais preparados para as atividades acadêmicas e principalmente desenvolvendo o pensamento crítico e não apenas repetindo de forma passiva e sim ativa seus conhecimentos.

\section{CONSIDERAÇÕES FINAIS}

A vivência oportunizar ao acadêmico ao participar de todos os processos da monitoria a maior compreensão, reflexão diante das disciplinas e dos trabalhos realizados em grupos para maior fixação do conteúdo e integração dos conhecimentos. Foi possível, o aprimoramento do estudo independente além do desenvolvimento da organização de material para estudo, o incentivo principalmente à docência para todos os envolvidos. A prática de metodologias ativas de ensino foi fundamental para a experiência, possibilitando a reflexão de mais de um caminho para o aprendizado possibilitando a todos os envolvidos experimentar processo pedagógico de todas as perspectivas.

\section{REFERENCIAS}

1. ASSIS FD, et al. Programa de Monitoria Acadêmica: percepções de monitores e orientadores, Rio de janeiro. Revista de Enfermagem da UERJ, 2006; 14(3): 391-397.

2. BATISTA JB, FRISON LMBF. Monitoria e aprendizagem colaborativa e autorregulada. Porto Alegre. Premier, 2006; 1(1): 232-247.

3. BERBEL NAN. As metodologias ativas e a promoção da autonomia dos estudantes. Semina, Londrina. Ciências Sociais e Humanas,2011; 32(1): 25-40.

4. FERNANDES NC, et al. Monitoria acadêmica e o cuidado da pessoa com estomia: Relato de experiência. REME: Revista Mineira de Enfermagem, 2015; 19(2): 238-241.

5. MESSIAS M. Construção coletiva de programas educativos: potencialidade para consecução da educação permanente em saúde. (Tese de Doutorado). - Escola de Enfermagem. Universidade de São Paulo, 2015; 269p.

6. NATÁRIO EG, SANTOS AAA. Programa de monitores para o ensino superior. Estudos de Psicologia, Campinas, 2010; 27(3): 355-364.

7. NUNES ECDA, et al. O ensino superior de enfermagem: implicações da formação profissional para o cuidado transpessoal. Rev. Latino-Am. Enfermagem, 2011; 19(2): 1-9.

8. Peleias, I. R, et al. Evolução do ensino da contabilidade no Brasil: uma análise histórica. São Paulo, Revista Contabilidade \& Finanças, 2007; 18(SPE): 19-32.

9. PELISSON EF, et al. A monitoria como instrumento de ensino: um relato de experiência. Arq Apadec, 2004; 8(1):30709.

10. RAMOS LAV, et al, Luiz Armando Vidal et al. Plano de monitoria acadêmica na disciplina anatomia humana: relato de experiência. Ensino, Saúde e Ambiente Backup, 2012; 5(3): 94-101.

11. STEINDORFF G, et al. Monitoria acadêmica no componente curricular de Semiotécnica em Enfermagem: Relato de experiência. Anais do Salão Internacional de Ensino, Pesquisa e Extensão,2016; 8(1).

12. VARGAS CP et al. Introdução da flipped classroom no ensino de enfermagem, Santa Maria. Rev Enferm UFSM, 2018; 8(4):829-840.

13. VICENZI CB, et al. A monitoria e seu papel no desenvolvimento da formação acadêmica, São Paulo. Revista Ciência em Extensão, 2016; 12(3): 88-94.

14. WAGNER F, et al. Monitoria universitária: a experiência da disciplina de exercícios terapêuticos do curso de fisioterapia, Santa Catarina. Cadernos Acadêmicos, 2012; 4(1):104-116. 